\title{
Fit for purpose? Pattern cutting and seams in wearables development
}

\author{
Sarah Kettley \\ School of Architecture, Design \& \\ the Built Environment \\ Nottingham Trent University \\ Burton Street, \\ Nottingham, NG1 4BU \\ Sarah.kettley@ntu.ac.uk
}

\author{
Tina Downes \\ School of Art \& Design \\ Nottingham Trent University \\ Burton Street, \\ Nottingham, NG1 4BU \\ tina.downes@ntu.ac.uk
}

\author{
Karen Harrigan \\ School of Art \& Design \\ Nottingham Trent University \\ Burton Street, \\ Nottingham, NG1 4BU \\ Karen.harrigan@ntu.ac.uk
}

\author{
Martha Glazzard \\ School of Art \& Design \\ Nottingham Trent University \\ Burton Street, \\ Nottingham, NG1 4BU \\ Martha.glazzard@ntu.ac.uk
}

\begin{abstract}
This paper describes how a group of practitioners and researchers are working across disciplines at Nottingham Trent University in the area of Technical Textiles. It introduces strands of ongoing enquiry centred around the development and application of stretch sensors on the body, focusing on how textile and fashion knowledge are being reflexively revealed in the collaborative development of seamful wearable concepts, and on the tensions between design philosophies as revealed by definitions of purpose. We discuss the current research direction of the Aeolia project, which seeks to exploit the literal gaps found in pattern cutting for fitted stretch garments towards experiential forms and potential interactions. Normative goals of fitness for purpose and seamlessness are interrogated and the potential for more integrated design processes, which may at first appear 'upside down' (Starner 2001), is discussed.
\end{abstract}

Design process, textile knowledge, wearables, stretch sensing, seamfulness, gaps

\section{INTRODUCTION}

The concept of seams has played an important role in wearables literature. Initially an inherited ideal of transparency and disappearance, seamlessness has not been adopted wholesale by the wearables community (Chalmers et al 2003, Galloway 2004). Rather the materiality of a system's inputs and outputs have become concerns of both interaction design theory and critical wearables practice (Hallnäs \& Redström 2006, Orth 2001), while purpose in design has been brought into question in the wearables literature, with many functionality led projects criticised for being opportunistic or lacking in aesthetic consideration (Berzowska 2005). Indeed, as long ago as 2001, Professor Thad Starner, a leading advocate of wearable computing wrote that the wearables design process may in fact benefit from being 'turned upside down' - that is, starting with expressive aims rather than functional requirements - in order to fully exploit the rich embodied knowledge of other disciplines (Starner 2001). The work of Lars Hallnäs, Johan Redström and others at the Interactive Institute's PLAY Research Studio in Sweden approaches ubiquitous technologies in terms of "what it means for something to be present in someone's life" at a metaphorical level, as opposed to through definitions of use (Hallnäs \& Redström 2002, p.106, Redström 2006), while interestingly, attempting to bring interaction design to fashion design pedagogy (Berglin et al 2008, Hallnäs 2009). This paper proposes that some of the difficulties in designing for presence as opposed to function can be overcome by combining design protocols drawn from Contemporary Craft with Hallnäs and Redström's approach: "if we think about the material that forms the expressions of computational things, it is clear that it is a combination of computations and interaction surfaces. Clearly, 'aesthetical design' of computational things is not to give a computer a new and more colourful shell" (2002, p.117). These protocols are introduced in the following section, and are referred to throughout the subsequent reflection on the potential of textile knowledge to inform the materiality of the wearable interface.

\section{CRAFT AS A METHODOLOGY FOR INTERACTION DESIGN RESEARCH}

Craft, especially in its critically aware contemporary form, offers the designer a valuable model for the development of computational wearables that exhibit metaphorical presence (Kettley 2010). Contemporary Craft seeks to dissolve dichotomies of mind and body, of process and product, and of aesthetics and use. As a methodology it can challenge tenets of standard design thinking, perhaps most obviously that design solves problems. Rather it acknowledges the central role of problems (gaps) in creative systems of meaning making and experience, which in turn facilitate presence. The following protocols were derived from transcripts of presentations and a series of interviews with jewellers in Scotland and formed part of a larger research project on craft as a design methodology for wearable technology (Kettley 2005): 
o The risky non-predetermined process results in original visual language, seen to embody particular political and metaphorical values.

o 'Material' may include traditional materials, technologies, processes and methods, each having their own affordances and constraints.

o Internalization of material - both source material and the material being worked - is essential for the development of original visual language.

o This internalization is achieved through action - techniques include drawing, direct manipulation of material, and repeated exposure to the material.

o Control over formal expressive elements at diverse effective ranges is dependant on an embodied understanding of the process of production.

o Signifiers of craft are not to be confused with the original visual language which emerges only from the internalization of material.

o Craft practice, objects and consumption are characterised by an undecidability of purpose and cultural placement. As such, they are unfixed and occupy a unique space between art and life.

This paper presents Craft as a discipline with the potential to inform new practice and goes beyond the common conceptions of craft as a thing well done, and even beyond its traditionally close relationship with material (in fact, in aiming to delineate any design principles at all, this challenges dominant configurations of craft itself). Further, the protocols presented here rest on the claim that the embodied nature of the making process invites an embodied response from the viewer; that is, both are exploratory, and both create meaning through action. They have underpinned not only the experimental approach of the textile practitioners in their development of new hybrid skills and methods, but also the research team's management and understanding of the emergent design methodology itself.

\section{THE AEOLIA PROJECT}

A useful starting point for the research was provided by the project Aeolia, supported by an Alt-w award from New Media Scotland and driven by concepts of embodiment in wearable technology systems on the body (Altw 2009). A commercially available but academically under-documented fibre had been identified as a focal point for collaboration: this carbonised rubber cord, $2 \mathrm{~mm}$ in diameter, changes its electrical properties when stretched, meaning it may be used in conjunction with a circuit to drive outputs such as light, sound or movement (Merlin Robotics 2010). The aim of the project was to bring textile sensibilities to bear on the stretch sensor fibre through the interrogation of strategies for embedding it in weave, knit and embroidery fabrics, although limits to the material's functionality were quickly discovered; frustrated by the rubber's friability and challenging handle, the team also developed their own knitted fabric stretch sensors using conductive yarns and elastic thread (Breedon et al 2008).

Aeolia has thus generated two broad strands of investigation: 'the backs', which take the form of garment explorations designed to house the Merlin stretch sensor, and the 'cello garment', which makes use of the team's proprietary knitted stretch sensor, developed by Martha Glazzard (figure 1) (Glazzard \& Kettley 2010). The functionality led cello garment was driven by Kettley and Glazzard towards a performance deadline, with important fitting input from Karen Harrigan, while the backs were developed both individually in response to discussions with Kettley, and in a micro-collaboration between Downes and Harrigan. The following sections focus on the latter creative process with the aim of drawing out what constitutes 'textile knowledge', and the ways in which this can enrich the design of tangible interfaces and wearable systems. 


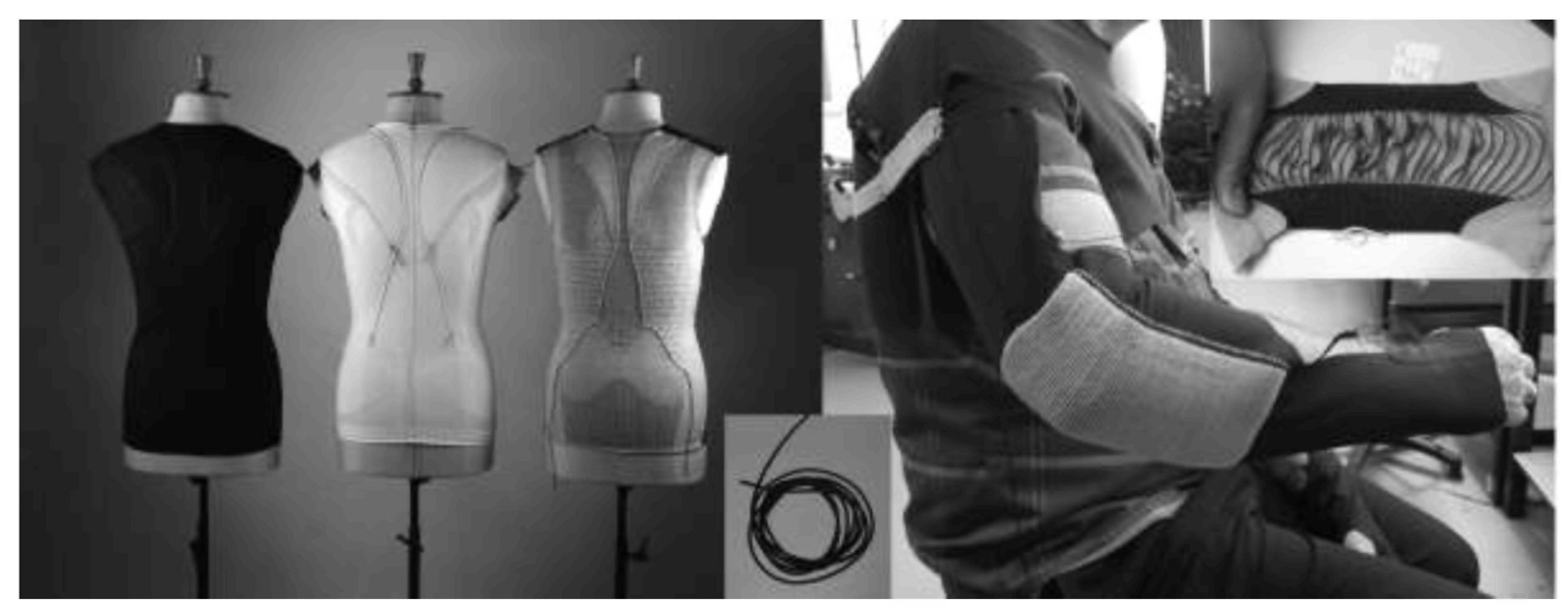

Figure 1 from left to right: The embroidered, knitted, woven backs incorporating the Merlin stretch sensor, detailed in inset; the cello garment with knitted stretch sensor, detailing reverse of knitted stretch sensor in inset.

\section{TEXTILE APPROACHES}

During initial material investigation, there was no defined use for the rubber sensor cord. Early fabric constructions were heavy and static and did not suggest new ideas about its potential application as is often the case in process led textile experimentation (figure 2). This form of open-ended, playful experimentation with new materials is recognised as vital for idea generation and the development of innovative practice. For example, Kinor Jiang differentiates between a 'textile creator' and 'textile designer' in his account of Junichi Arai of the Nuno Corporation (2010). Indeed many theoretical and empirical accounts of textiles and other craft practices are based in continental philosophy. Heidegger (1996) argues that we do not come to know the world initially through contemplation and perceptual cognition but through handling - theoretical concepts arise from action, practice and hands-on experience, while in Serres' poetic philosophy, weaving and knotting are analogous to life itself $(2008, p 303)$. Bolt suggests that 'material thinking is the magic of handling ... [it] offers us a way of considering the relations that take place within the very process or tissue of making' (2006, p.1). Material thinking involves the joining together of hand, eye and mind where the materials and processes of production have their own intelligence that come to play in the interaction with the practitioner's creative intelligence. In this iterative interplay, knowledge becomes embodied.
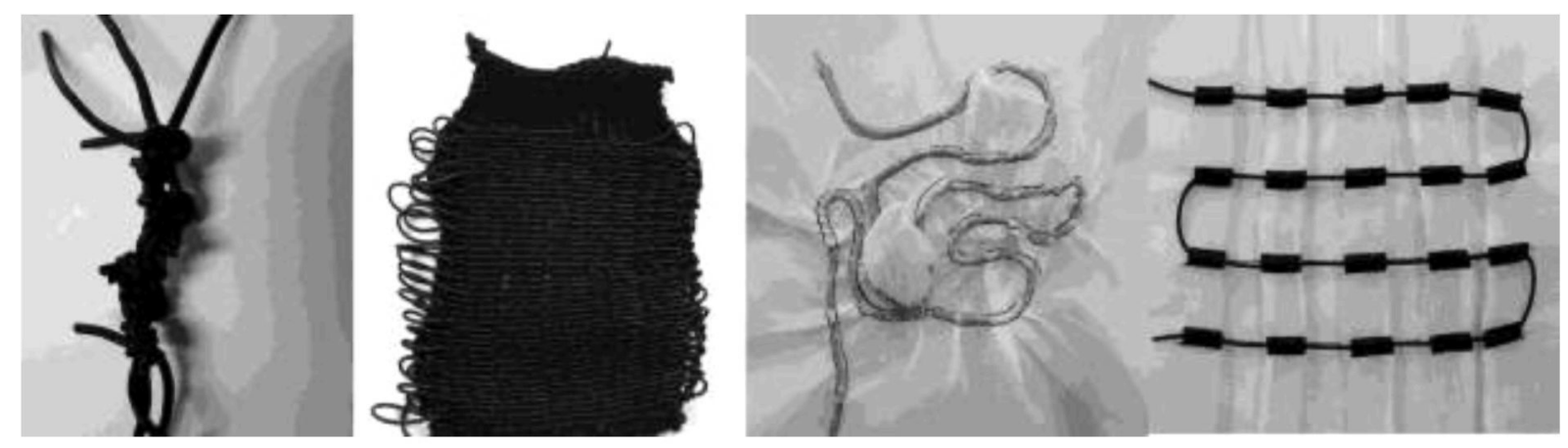

Figure 2: Glazzard's early constructions with the rubber stretch sensor cord, followed by Downes' experimental embroidery samples laying sensor into fabric surface

The discipline of embroidery provided methods to move away from the linear nature of constructed textiles with more freeform approaches to the sensor cord and channels and threading became a new focus. Downes' research enquiry centred on the interplay between stretch and static fabric; selecting a knitted jersey and semitransparent cotton organdie, the rubber cord was integrated using twin-needling, couching, pleating, stitched channels and lacing techniques (figure 2). In the development of wearables, technology is often hidden between layers of the garment (Seymour 2009). Here, in contrast, the team were motivated to find ways to make the sensor a visible part of the cloth and a considered part of the design aesthetic in line with the craft 
design protocols. The fabric outcomes from this stage of development demonstrated that the rubber cord could be integrated into fabric with a more successful aesthetic and handle, however, it was found that the more complicated the inlay, the less reliable the conductive path became. This suggested that the stretch sensor would be best integrated along lines of stretch or resistance of the intended product rather than becoming a substantial part of the cloth itself. As a material for the development of a purely formal textile visual language, the rubber was found to introduce a number of significant constraints. Considering its electronic as well as its expressive function, however, led the team to explore new avenues for aesthetic development drawing on a well-defined visual resource in collaboration between textile and fashion design.

\section{EMBODIED KNOWLEDGE AND COLLABORATIVE WORK}

In scoping the collaborative activity, certain parameters were set by the interactive intent of the Aeolia project to explore concepts of embodiment in wearable technology systems (Alt-w 2009). The stretch properties of the rubber cord sensor made explicit the requirement for some degree of movement in order for interaction to occur, and the textile practitioners were interested in exploring the materiality of the textile interface and the stretch sensor with the body. Concerns were how to integrate awkward, uncomfortable technologies seamlessly into the garment without causing irritation or restricting movement. An aesthetic approach that considered the visual and tactile qualities of the wearing experience was desirable and the material knowledge that textile designers had acquired through the described initial playful investigation informed an approach incorporating the rubber cord stretch sensor through integral channels or seams within the garment for threading or couching.

Interestingly, these parameters seemed vague when compared to a fashion practitioner's usual methodology and highlighted differences in approach between design disciplines. Harrigan asked questions about the intended functionality and application for the stretch sensor, primarily concerned with making the product work rather than exploring its materiality. What did the stretch sensor do? How was it used? What was it for? Why did we want it to be visible when it had little aesthetic appeal? When placed within a fashion context, the rubber material immediately inherited associated meanings that did not apply in the robotics industry. Thus began a process of dismantling and justifying methods to each other. From a different perspective, textile designers felt more comfortable with an open-ended design process - let us test how the fabric drapes, moves, feels, looks if we combine this cord with this yarn with this process. The expectation here was that experimental ('risky') practice would suggest and reveal new concepts and potential applications that may work towards functional purpose.

To create a more defined context for collaboration, Downes and Harrigan examined streamlined designs of stretch sports garments and considered existing wearable concepts for capturing biological data from the body (Braddock Clarke \& O'Mahoney 2002, Butterfield 2009, Institute of Nanotechnology 2009). The difficulty of resolving the tension between the often unappealing handling qualities of functional materials with an aesthetic, wearable outcome was noted and further reinforced the aim to internalise and communicate the material's meaning within the design process.
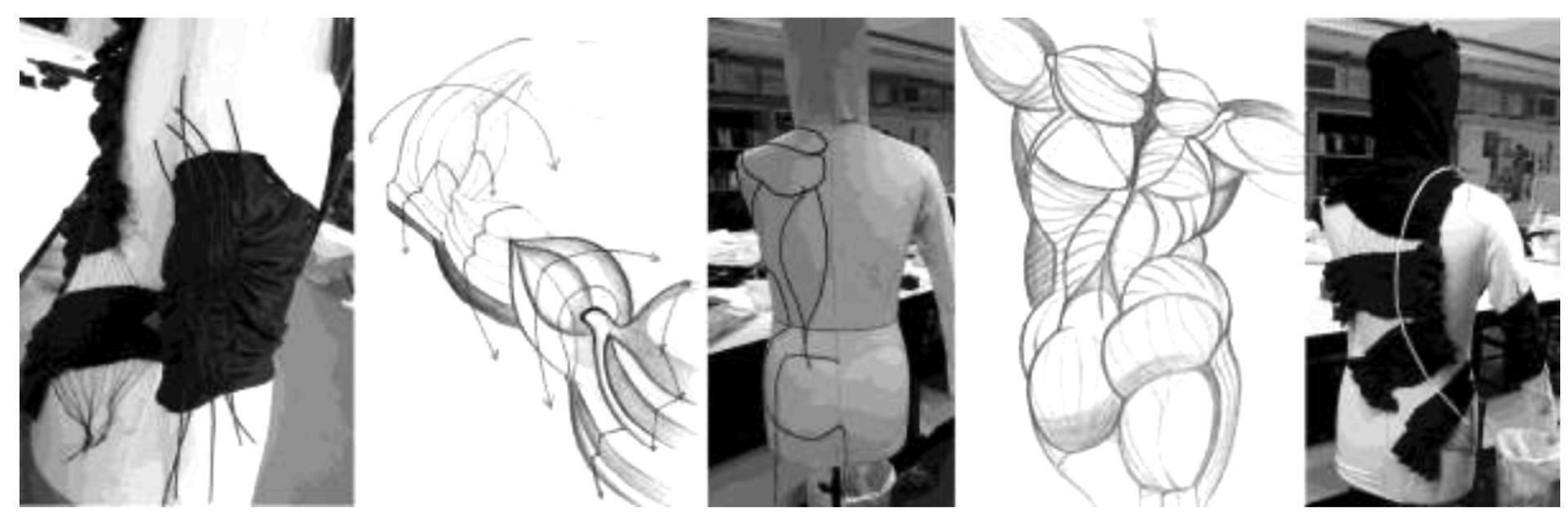

Figure 3: Developing resources for design - collaborative practice on the mannequin stand

Therefore, an aesthetic approach was taken by Harrigan and Downes, who referenced Hogarth's (2003) dynamic anatomy to inform ideas of physicality, movement, stretch and resistance of the body. The muscle and tendon structure of the male torso suggested the power and dynamism required to activate the stretch sensor as well as referencing its own inherent form (figure 3). Working with this source material together with the 
material of the carbon impregnated rubber stretch cord, three garment forms were developed to integrate the sensor that could notionally collect data or create output defined by muscle movement. Each garment explored different textile structures drawing upon embroidery, knit and weave processes (Downes \& Harrigan 2009, Kettley \& Briggs-Goode 2010) (figures 1 and 3), thereby bringing existing embodied knowledge of textile process to bear on the creation of formal expression.

The collaborative design process moved onto another level when Downes and Harrigan started to share practice-based knowledge from their disciplines (Kettley \& Downes 2010). Working within the design studio, Harrigan utilised a male mannequin stand dressed in a simple stretch garment form in white jersey, along with fine black bias tape and pins to map pattern segments onto the body. Downes contributed a series of embroidered samples that explored stretch and static structures developed from drawings of male muscle structures and tendons. The practitioners started by working around the stand referencing anatomical drawings whilst pinning embroidered samples to the body and photographing different configurations (figure 3). Wenger (1998, p.48) states 'In practice, so called manual activity is not thoughtless, and mental activity is not disembodied'. The samples suggested ideas for placement, scale and detail on the body, developed thoughts about areas that would need to remain firm and static and lines where stretch and movement would be required. Gesture and body language, rather than words, captured assent or dismissal of a line in the right or wrong place. Serendipitous ideas arose as they worked. For instance, uncut threads from manipulated pleats imitated lines of the muscle structure and the practitioners became intrigued by the negative shapes of the gaps between the samples, an idea for further development. Following this, 'drawing' directly onto the garment blank with tape and pins, a number of stretch patterns were devised which suggested lines where the stretch sensor could be incorporated.

\section{THE INTEGRATED DESIGN PROCESS AS OUTCOME}

Ultimately, one pattern draft was selected and developed by Harrigan in two ways: as a one-piece stretch pattern and a traditional seamed pattern. The patterns provide aesthetic focus and visual synergy for three garments; one woven, one knitted, one embroidered, each with channels or seams accommodated within the fabric for threading, or couching sensors along extension lines on the body in a fully integrated design process (Figure 4). Practitioners worked between labour intensive hand processes and advanced textile CAD and CAM to engineer fabrics to specified forms.
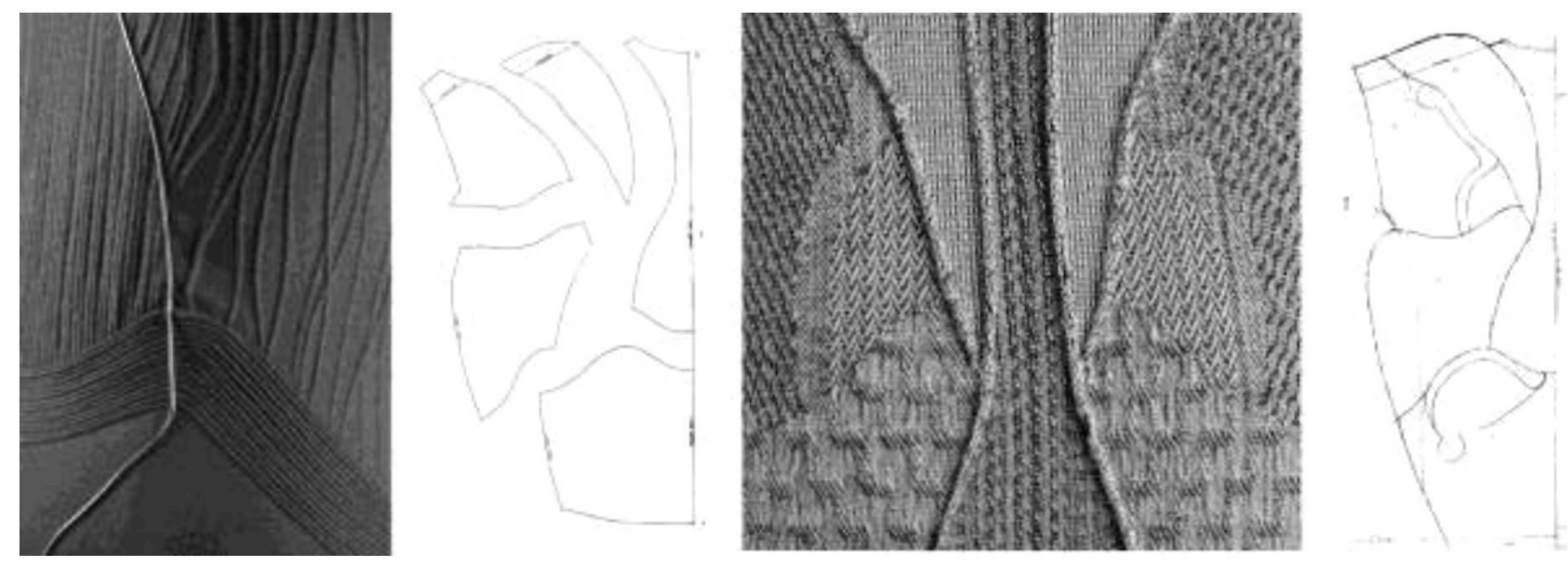

Figure 4: Channels and seams: Embroidery detail, Tina Downes; Weave detail, Nigel Marshall; Segmented and one-piece pattern drafts, Karen Harrigan.

The three garments explored different textile structures, separately drawing upon knit, weave and embroidery processes (Downes \& Harrigan 2009). Glazzard and Marshall each scanned the one-piece pattern draft and used specialist textile software to translate areas of the design into knit and weave structures. They not only synthesized visual and tactile qualities to create a strong aesthetic response to the flowing muscle and tendon lines that dissected the garment back, but also engineered knitted and woven structures to suitable levels of stretch and resistance to fit the body. Channels were integrated between the different structures to enable the stretch sensor to be threaded along lines of muscular resistance as defined by the pattern. It took several attempts to bring together so many complex factors and engineer fit of the one-piece knitted and woven constructions. In contrast, Downes worked with pattern segments using embroidery processes to embed cord onto the back of woven cloth. This created raised lines on the surface and used the qualities of the stretch 
sensor to visually reference the texture of muscle structure. The cloth suggested a fabric that could sense the body surface, not just the movement of the stretch sensor couched along carefully positioned seam lines.

Kettley encouraged the practitioners to build knowledge in stages, working towards a meeting point with other disciplines. The garments were essentially explorations of an integrated approach to design aesthetics, fit and the materiality of the interface, demonstrating the power of the object to engage audiences and potential users without a predefined function in place; rather, it has been the sensorial qualities of potential interaction that the team have sought to put in place first. Such crafted interfaces can then be used as interventions and props to guide decisions about functionality, including the treatment of output modes (the coupling of experiential qualities of light and sound to inputs for example), and the nature of the information they may deliver. In this way, the work will feed into other research in Interaction Design which draws its inspiration from theatrical and artistic processes (Dunne \& Raby 2002, Gaver et al 2003, Light et al 2009). Early pilot sessions with dancers are presently informing new research questions in these areas as well as introducing new 'material' (in the craft protocol's broad sense of the word) in the form of bodies and spaces, and triggering exciting new conceptual directions around the themes of seams in wearables.

\section{PATTERN CUTTING INFORMING NEW CONCEPTUAL DIRECTION}

Revisiting the metaphor of seams in the wearables literature, the team are now becoming intrigued by the gaps between pattern segments and are beginning to explore the notion of the seams becoming the garment itself, or conversely, working on whole pieces of cloth that can be fitted to the body through structural manipulation of the gaps. Harrigan brought a bundle of pattern cutting ideas to a meeting, which she unrolled on the floor to demonstrate her thinking about these gaps, and the four authors were immediately able to make associations between current conceptual fashion (Maison Martin Margiela 2010), Interaction Design, and Textile process. Disciplines which at first may have initially been perceived as subordinate to some other, grander, conceptual plan have thus become fully engaged with the now interdisciplinary design process, making valuable embodied knowledge available to the development of what we hope will be more meaningful and engaging wearable concepts.
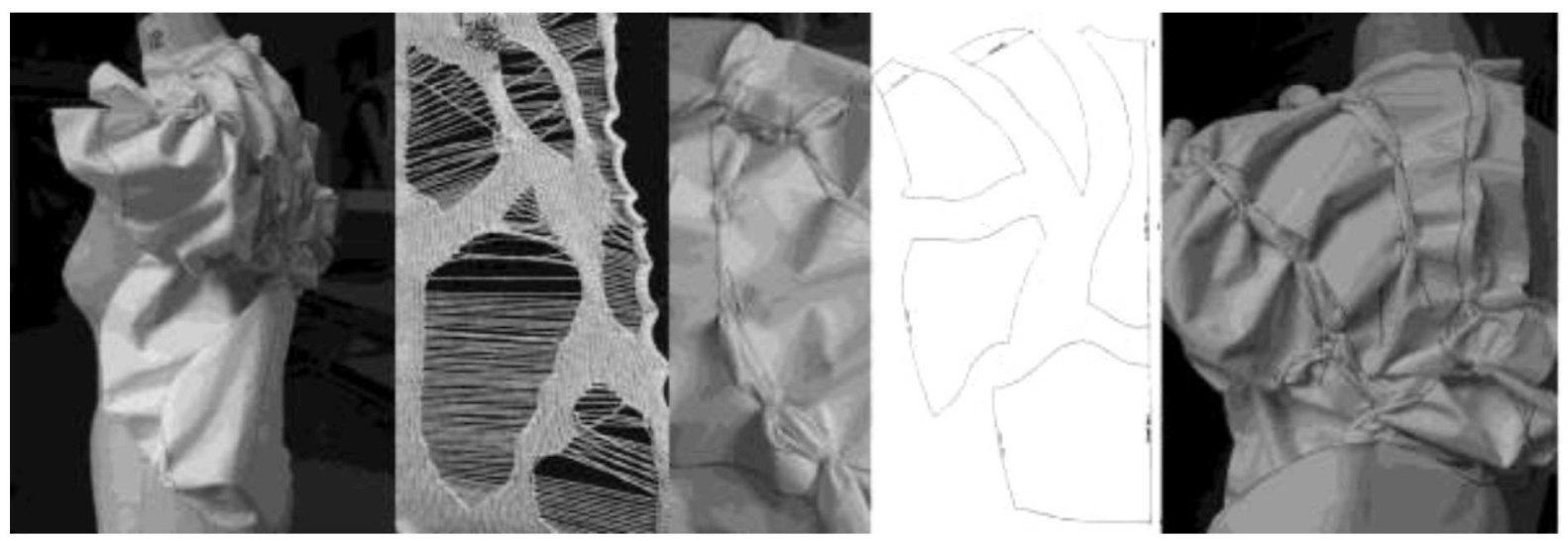

Figure 5: Structural manipulation of the gaps between pattern segments to create seams; knitting the gaps

Analysis of movement, stretch and restriction of the three garment backs (figures 1 and 4 ) on moving bodies revealed the potential for further exploitation of the differences in embroidered, woven and knitted fabric structures to control or enhance gestural expression. This current development aims to exploit the density of fabric structures in hybrid forms that combine stiff tectonic areas of resistance, with soft, connecting pathways that map the body. Working on a whole piece of cloth, Harrigan is manipulating the fabric in the seams. In this way the seams could be used to house other forms of technology or become the technology themselves through use of conductive thread, elasticated and unfolding structures. By stiffening pattern segments before gathering the seams, a completely different kind of form and wearable experience is created (figure 5). This will suggest or dictate different kinds of movement or deportment. Meanwhile, Glazzard has started knitting the gaps (figure 5) to develop the notion of the gaps becoming channels of sensing fabric. Greater expressive potential may be found across the back, chest and arms and by turning the pattern segments sideways, the team are interested in how they might work in the negative space between segments creating stretching or unfolding fabric sensors that connect to stiff plates or pinion points making use of our own developing knitted, embroidered or woven stretch sensors. 


\section{CONCLUSION}

All of these ideas have been generated through practice-based collaboration, which exploits embodied knowledge of fashion and textile disciplines together with debate with experienced researchers in the field of interaction design. To work collaboratively requires sufficient awareness of each other's disciplines to create connections in thinking and language, and this rich aspect of the process has suggested that an extension to the proposed Craft design protocols is needed to take account of the complexity of wearables development. The team see resonances between their work and approaches in fashion (that do not necessarily relate to wearables) from stream-lined designs in current sports/performance garments, to the conceptual explorations of technology, fit and exposure of functional aspects of the garment by Chalayan and Margiela, to visual interpretations in seasonal ready to wear collections (Shulman 2009, Braddock Clarke \& O'Mahoney 2002 and 2006). Stretching beyond our experience and scoping the need for applications for fashion and textile knowledge in new fields, the team seek connecting places for engagement with a common goal and focus to explore and extend understanding.

This project has sought to answer concerns with materiality and presence as outlined previously through the textile practitioners' depth of material knowledge and their ability to manipulate fabric structures to the required levels of handle, weight, drape, stiffness, softness, and flexibility. We have shown that the processual knowledge of quite specific practices can be combined to great effect, exploiting the differences between embroidery, knit and weave knowledge. In working on the functional garments in the other strand of the project, we will also be able to reflect on the combination of such processual knowledge with designerly ways of working, including foregrounding function while striving for aesthetically successful outcomes.

\section{REFERENCES}

Alt-w (2009). Reveal/Reset. InSpace Gallery, Edinburgh, 5 August - 5 September 2009.

Berglin, L., Cederwall, S. L., Hallnäs, L., Jönsson, B., Kvaal, A. K., Lundstedt, L., Nordström, M., Barbro

Peterson, B. \& Thornquist, C. (2008). Interaction Design Methods in Fashion Design Teaching.

http://www.nshu.se/download/6476/017g04slutrapport_hallnas.pdf. Accessed 30 July 2010.

Berzowska, J. (2005). Electronic Textiles, Wearable Computers, Reactive Fashion and Soft Computation. Textile, Volume 3, Issue 1, pp. 2-19, Berg.

Braddock Clarke, S. \& O'Mahony, M. (2002). Sports Tech - Revolutionary Fabrics, Fashion and Design. London: Thames and Hudson.

Braddock Clarke, S. \& O'Mahony, M, (2006). Techno Textile 2 - Revolutionary fabrics for fashion and design. New York: Thames and Hudson.

Butterfield, J. (Ed.) (2009). Smart Wearables Show. The Boilerhouse, Grantham, $8^{\text {th }}$ July 2009: Institute of Minerals and Mining.

Chalmers, M., MacColl, I. \& Bell, M. (2003) Seamful Design: Showing the Seams in Wearable Computing. In the Proceedings of IEE Eurowearable 2003, 4th-5th September 2003, University of Birmingham. pp. 11-17. London: IEE.

Downes, T. \& Harrigan, H. (2009). Lines of Resistance: A collaborative approach to integrating stretch sensor technology into garment form. In: Futurescan: Mapping the Territory. Foresight Centre, University of Liverpool, 17\&18 November 2009.

Dunne, A. \& Raby, F. (2002). The Placebo Project. Proceedings of the 4th conference on Designing interactive systems: processes, practices, methods, and techniques. p.9-12, June 25-28, 2002, London, England Galloway, A. (2004). Fashion Sensing / Fashioning Sense: A conversation about aesthetics with International Fashion Machines' Maggie Orth. HorizonZero Issue 16, August 2004.

Gaver, W., Beaver, J., \& Benford, S. (2003). Ambiguity as a resource for design. Proceedings of the SIGCHI conference on Human factors in computing systems, April 05-10, 2003, Ft. Lauderdale, Florida, USA Glazzard, M. \& Kettley, S. (2010). Knitted Stretch Sensors for Sound Ouput. Extended abstract, Proceedings $4^{\text {th }}$ International Conference on Tangible, Embedded \& Embodied Interactions, MIT, Boston CA. January 2010.

Hallnäs, L. (2009). The all-important difference... concepts of creativity in the fashion design process. http://en.scientificcommons.org/54015952. Accessed 30 July 2010.

Hallnäs, L. \& Redström, J. (2006). Interaction Design: Foundations, Experiments. Textile Research Centre, Swedish School of Textiles, Unversity College of Borås and Interactive Institute.

Institute of Nanotechnology (2009). Innovations in Textiles 2009: Smart, Nano and Technical Textiles for Medical, Industrial and Clothing applications. London, $18^{\text {th }}-19^{\text {th }}$ March 2009, Royal College of Physicians. Hogarth, B. (2003). Dynamic Anatomy. New York: Watson-Guptill Publications.

Jiang, K. (2010). Metallic Sound. Research lecture and exhibition. Bonington Gallery, Nottingham Trent University. 
Kettley, S. (2005). Crafts Praxis as a Design Resource. In P. Rodgers, L. Brodhurst, \& D. Hepburn (Eds.). (2005). Crossing Design Boundaries, pp.545-549. London: Taylor \& Francis Group.

Kettley, S. (2010). Fluidity in craft and authenticity. Interactions, September+October 2010. ACM.

Kettley, S. \& Briggs-Goode, A. (2010). Textile Enquiry and Design: Aeolia. Duck Journal for Textile Research and Textile Design. Loughborough University, in press.

Kettley, S. \& Downes, T. (2010). Revealing Textile Knowledge through Interdisciplinary Research. Re-defining Research, Art \& Design and the Built Environment Conference, Nottingham Trent University, 8 July 2010. Light, A., Simpson, G., Weaver, L. \& Healey, P. (2009). Geezers, turbines, fantasy personas: making the everyday into the future. Proceedings 7th ACM Conference on Creativity and Cognition. Berkeley, California, USA, pp.39-48.

Maison Martin Margiela (2010). '20' The Exhibition. Somerset House, London, 3 June - 5 September 2010. Serres, M. (2008). The Five Senses: A Philosophy of Mingled Bodies. Continuum International Publishing Group.

Seymour, S. (2009). Fashionable Technology. SpringerWien, New York.

Shulman, A. (2009). http://vogue.co.uk/fashion/show.aspx/catwalk (accessed 16.2.10).

Starner, T. (2001). The Challenges of Wearable Computing: Part 2. IEEE Micro. Vol.21, No.4, July - August 2001, pp54-67.

Wenger, E. (1998). Communities of Practice: Learning, Meaning, Identity. Cambridge, UK: Cambridge University Press. 